\title{
Designing Successful Governance Groups: Lessons for Leaders from Real-World Examples
}

\section{Citation}

Budish, Ryan, Sarah Myers West, and Urs Gasser. 2015. "Designing Successful Governance Groups: Lessons for Leaders from Real-World Examples." Berkman Klein Center for Internet \& Society Research Publication 2015-11.

\section{Published Version}

https://cyber.harvard.edu/node/99052

\section{Permanent link}

http://nrs.harvard.edu/urn-3:HUL.InstRepos:28552583

\section{Terms of Use}

This article was downloaded from Harvard University's DASH repository, and is made available under the terms and conditions applicable to Other Posted Material, as set forth at http:// nrs.harvard.edu/urn-3:HUL.InstRepos:dash.current.terms-of-use\#LAA

\section{Share Your Story}

The Harvard community has made this article openly available.

Please share how this access benefits you. Submit a story.

\section{Accessibility}


Research Publication No. 2015-11

August 2015

Designing Successful Governance Groups:

Lessons for Leaders from Real-World Examples

\author{
Ryan Budish \\ Sarah Myers West \\ Urs Gasser
}

This paper can be downloaded without charge at:

The Berkman Center for Internet \& Society Research Publication Series: https://cyber.law.harvard.edu/node/99052

The Social Science Research Network Electronic Paper Collection: Available at SSRN: http://ssrn.com/abstract=2638006

\footnotetext{
23 Everett Street. Second Floor - Cambridge, Massachusetts 02138

$+1617.495 .7547 \cdot+1617.495 .7641$ (fax) • http://cyber.law.harvard.edu cyber@1aw.harvard.edu
} 



\section{Preface}

In January 2015, the Global Network of Internet \& Society Research Centers (NoC) published the results of a globally coordinated, independent academic research project exploring multistakeholder governance models. Facilitated by the Berkman Center for Internet \& Society at Harvard University, the work evaluated a wide range of governance groups with the goal of contributing meaningfully to the current debate around the future of the Internet governance ecosystem.

The report, entitled Multistakeholder as Governance Groups: Observations From Case Studies, included twelve case studies of real-world governance structures from around the world and from both inside and outside the sphere of Internet governance. The report also included a synthesis paper, which drew from the case studies lessons that challenged conventional thinking with respect to the formation, operation, and critical success factors of governance groups.

Through its work, the Network of Centers hopes to demonstrate new strategies and approaches for academia regarding its roles in research, facilitation and convening, and education in and communication about the Internet age. This ambition includes creating outputs that are useful, actionable, and timely for policymakers and stakeholders.

In that spirit, this document is intended to help translate our original report into a form useful for those creating, convening, or leading governance groups. It is our goal that this document can provide an operational starting place for those who wish to learn more about some of the components critical to the success of a governance group. The original report goes into far greater depth on both the details of the case studies and the lessons learned from them, whereas this document highlights only a few of the points most relevant for operationalizing the findings of the full report.

The full report is available at $h t t p: / / s s r n . c o m / a b s t r a c t=2549270$. 


\section{Introduction}

At the 2014 NETmundial meeting, participants from around the world and from many different sectors (business, government, academia, the technical community, and civil society) agreed to a set of principles and a roadmap to guide the development of the Internet governance ecosystem. One of those principles was a renewed commitment to "multistakeholder governance." As the NETmundial statement said, "Internet governance should be built on democratic, multistakeholder processes, ensuring the meaningful and accountable participation of all stakeholders, including governments, the private sector, civil society, the technical community, the academic community, and users. The respective roles and responsibilities of stakeholders should be interpreted in a flexible manner with reference to the issue under discussion." But how does one go about structuring, convening, operating, and maintaining an effective multistakeholder governance group?

Even to those with years of experience in the field, participation in the Internet governance ecosystem can seem daunting. Internet governance is an increasingly complex sphere involving numerous forums, organizations, procedures, and topics. Effective participation in the system therefore requires resources, skills, and knowledge, covering both substantive and procedural elements. And one of the most fundamental elements of the ecosystem is the multistakeholder group. For that reason, it is necessary to have a better understanding of both how multistakeholder governance groups operate and how they best achieve their goals.

To help better understand multistakeholder groups and the factors most critical to their success, the Global Network of Interdisciplinary Internet \& Society Research Centers (NoC) identified, researched, and wrote twelve case studies of real-world governance structures, a few of which are highlighted throughout this report. Although the sample size is too small to be conclusive, our research suggests that there is no single model or way to run multistakeholder groups that would be equally effective in all circumstances. Instead, our case studies show that effective groups have conveners who are best able to use the "tools" in the governance toolbox, carefully shaping the formation, operation, and outcomes of the group.

To be clear: effective governance groups require effective leadership. Although "multistakeholder" has many definitions, most conceptions include a bottom-up collaborative process. But a bottom-up approach should not be confused with a leaderless process. In our research we found the most successful groups had a particular kind of leader: conveners who successfully adapted to both the groups' environments and changing needs (see Typology of Leadership Forms). These conveners were strong leaders, not in the dictatorial sense, but in a way that helped facilitate the best work from the group as a whole.

Although there is no one-size-fits-all template, our research suggests a three-step iterative process that will help conveners shape more effective governance groups.

\section{THE PROCESS FOR CREATING A SUCCESSFUL GOVERNANCE GROUP:}

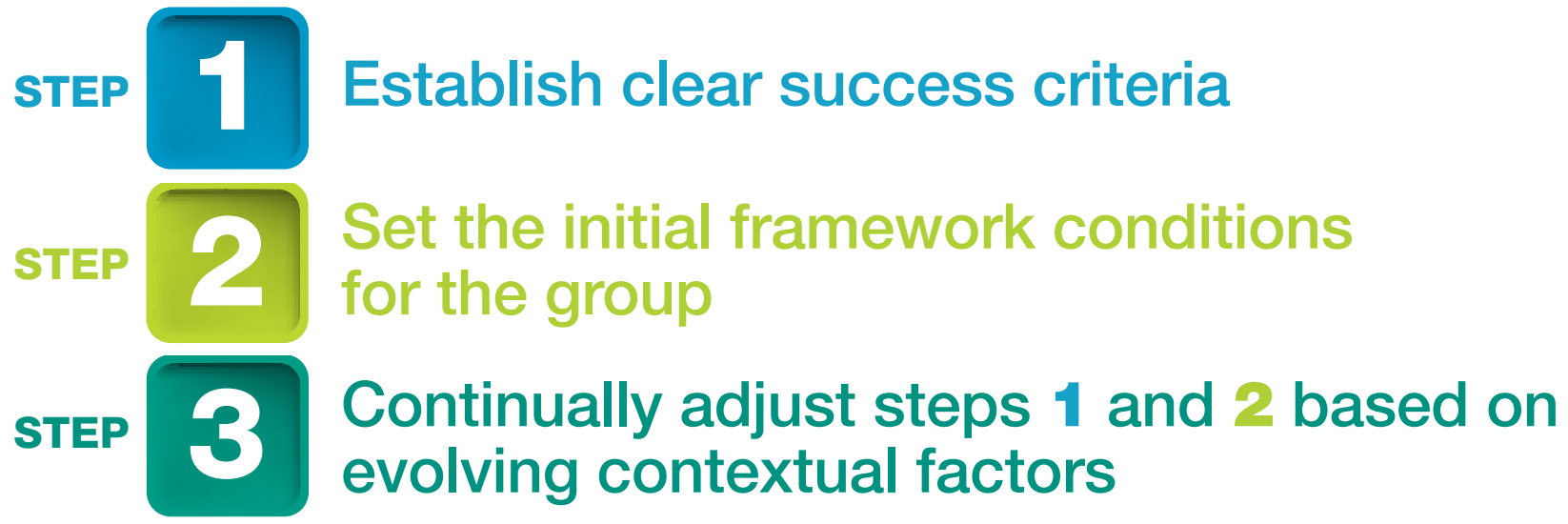

This document explores these three steps in greater detail. At their core, however, these three steps help implement one central idea: governance groups work best when they are flexible and adaptive to new circumstances and needs and have conveners who understand how their decisions will affect the inclusiveness, transparency, accountability, and effectiveness of the group. Our three steps offer one possible structure that may be useful for conveners in trying to create that situational awareness and flexibility, and highlight some of the factors that those conveners should focus on. 


\section{Typology of Leadership Forms}

Our research identified several kinds of leadership roles in the lifecycle of a governance group, including what we call:

Instigators - Conveners • Influencers

Instigators are leaders who identify a problem and prompt the formation of a governance group.

Conveners, the focus of this document, define both structure and process for the group and continually facilitate the group's operation and reassess its core principles and procedures. Convening is often a formally defined position that is subject to some kind of oversight authority.

Influencers are those who shape the outcome of a governance group and wield their leadership either through expertise or through the availability of resources.

This typology is limited to roles that different types of leaders may play within the formation, creation, and operation of governance groups. However, within each role, there is an array of different leadership styles that a leader might employ.

\section{Background}

At the heart of our research are twelve case studies. The case studies look at a wide variety of governance groups. Some are public sector efforts, and some are private sector-driven. Some operate at the national level while others operate at the international level. They represent regions all over the world and address issues of varying levels of technical complexity. The case studies cover a wide range of activities, including drafting legislation, developing policy in the absence of formal regulatory authority, defining and exploring the scope of a problem, and building connections among stakeholders. While some of the case studies come from areas related to Internet governance, others come from outside the Internet governance ecosystem. Although they differ in many respects, the governance groups documented in the case studies share a common commitment to using multistakeholder processes to solve complex issues.

The case studies were selected, researched, and written by academics from several NoC institutions. The NoC is a collaborative initiative among academic institutions with a focus on interdisciplinary research on the development, social impact, policy implications, and legal issues concerning the Internet. This initiative aims to increase interoperability between participating centers in order to stimulate the creation of new cross-national, cross-disciplinary conversation, debate, teaching, learning, and engagement regarding the most pressing questions around new technologies, social change, and related policy and regulatory developments.

For this work the case studies were selected for their potential to shed light on important issues emerging from the ongoing Internet governance debate. Each of the case study authors conducted desk research and interviews in order to develop the case studies. In several cases, the case studies reflect direct input from participants and conveners in the group's operation. Once drafted, the case studies underwent several rounds of peer review. Once completed, the case studies were reviewed as a whole and synthesized into a paper that drew from the case studies lessons that challenged conventional thinking with respect to the formation, operation, and critical success factors of governance groups.

The original report, including all of the case studies, is available at http://ssrn.com/abstract=2549270. 


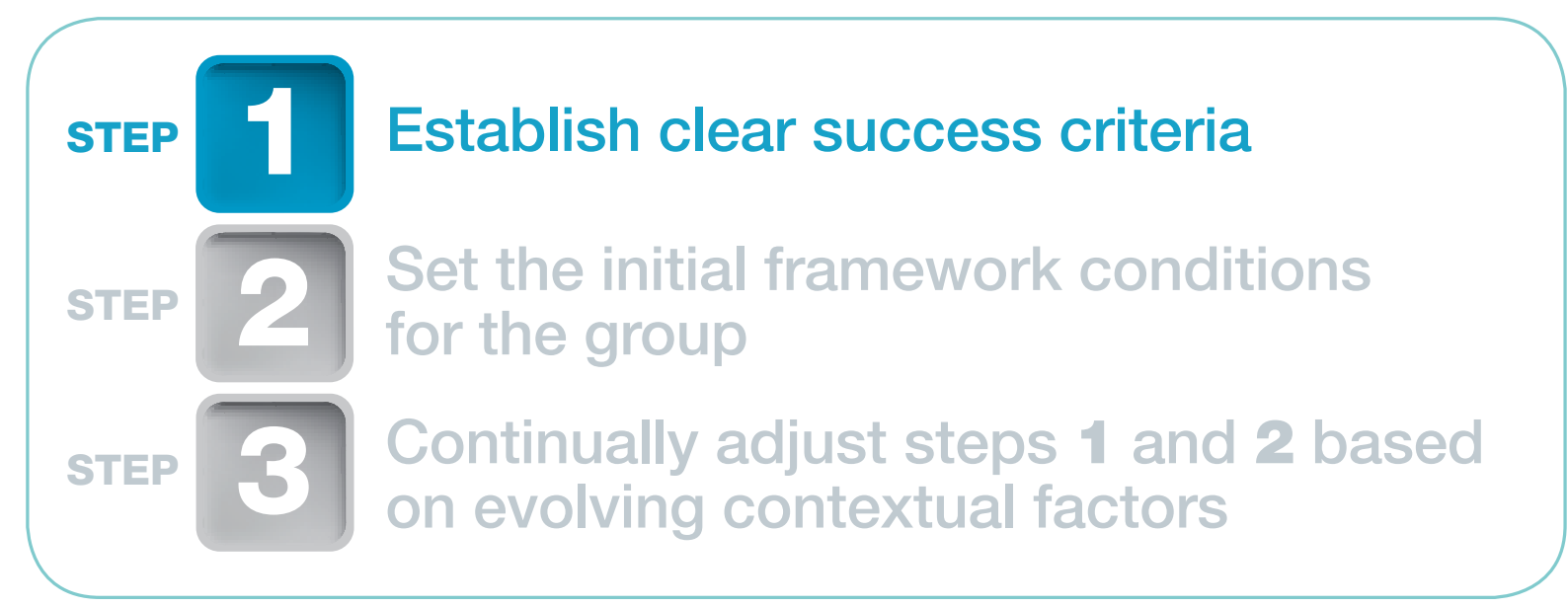

For conveners seeking to build effective governance groups, it is important to first establish clear success criteria. A multistakeholder group is often formed to meet some external objective, such as drafting legislation, or developing a new policy. But meeting this objective is often not sufficient for the group to be considered successful. For that reason, the convener of an effective governance group is not only trying to accomplish external objectives, but is also concerned with how those objectives are achieved. In that regard, "effectiveness" for a governance group is a more holistic measure, encompassing more than simply meeting a set of external goals.

Governance groups are judged simultaneously at two levels: internally and externally. External definitions of success are objective-oriented, focused on whether or not a stated goal was achieved. Internal definitions of success are generally more process-oriented, focused on whether the group operates as effectively as possible given its context and constraints. Both of these levels are important because multistakeholder groups often operate outside or on the fringes of common governance structures. For example, a group might need to draft legislation outside of elected parliamentary systems or regulate businesses in a space where government lacks regulatory authority. For that reason, multistakeholder groups often operate without access to, or reliance on, traditional sources of legitimacy, such as elections or constitutional authority. As a result, governance groups are not only measured by whether or not they achieve their objectives, but the extent to which they do so democratically and with the inclusion of broad-based stakeholder support.

Setting at the outset both the internal and external success criteria is important and should reflect the unique circumstances of the group. Every governance group is going to be different in this regard, and for that reason, conveners should think carefully and creatively about their most important success criteria. Ultimately, we can't proscribe criteria because success for a particular governance group is highly context dependent. However, some examples from our research are listed below.

Success criteria are not just an end in and of themselves; they are the standard by which a group should calibrate their processes. The most successful of our case studies involved governance groups that tailored their processes to their criteria of success.

\section{Achieving a good fit between the processes and goals of a group is often the first and most important step toward achieving a successful outcome.}

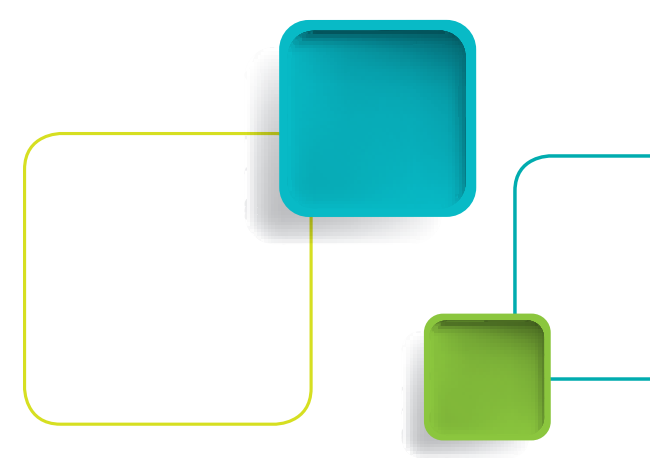

\section{External Success Criteria Internal Success Criteria}

Drafting legislation

Agreeing on common

terminology

Coordinating on standards within industry

Building a network of people and resources

Developing educational tools
Having Legitimacy

Cooperation among participants

Avoiding regulation

Reaching a common

understanding

Sharing knowledge 


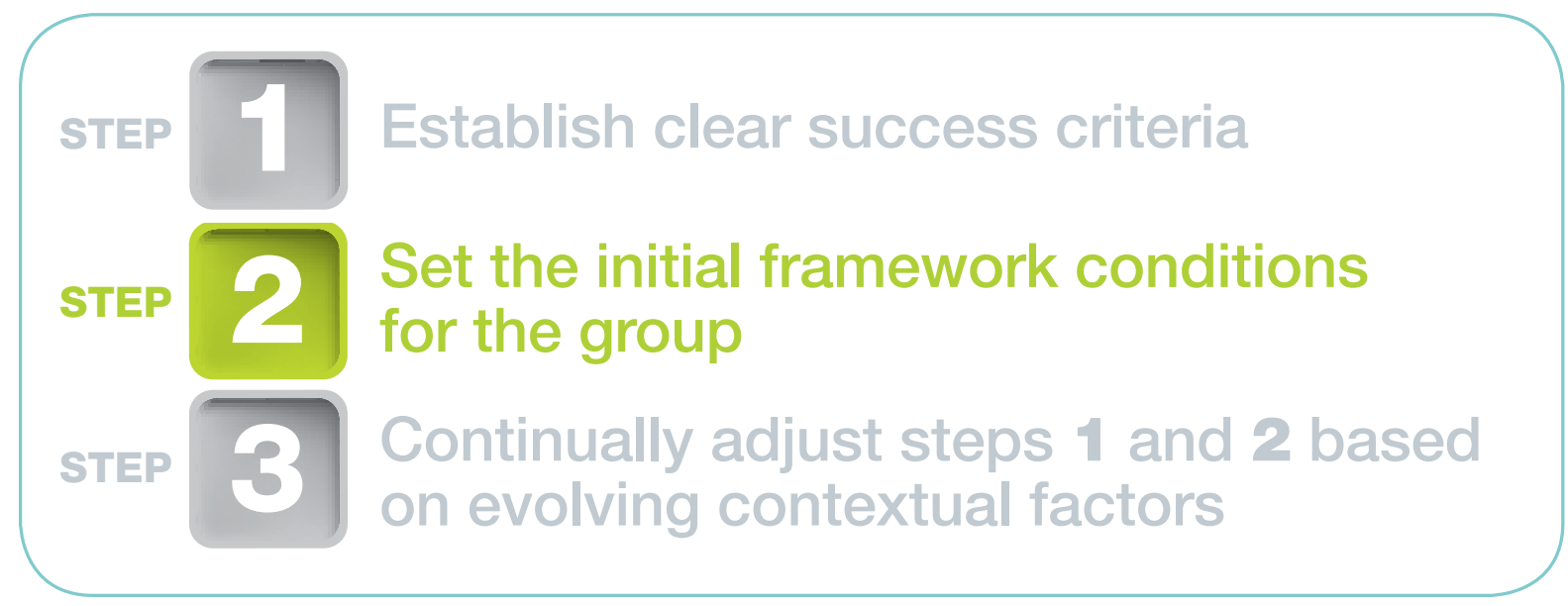

Governance groups can be shaped in innumerable ways, with conveners facing an array of choices ranging from who to include to how decisions will be made. Navigating that complexity in a way that maximizes the effectiveness of the group is no easy task. The success criteria for the group are a helpful starting place for properly calibrating the initial operating conditions for the group. But what are the levers of customization that conveners can activate? Our research identified five broad categories of factors that conveners should be particularly attuned to. They are: inclusiveness, transparency, accountability, legitimacy, and effectiveness.

\section{FIVE FACTORS CONVENERS CAN LEVERAGE}

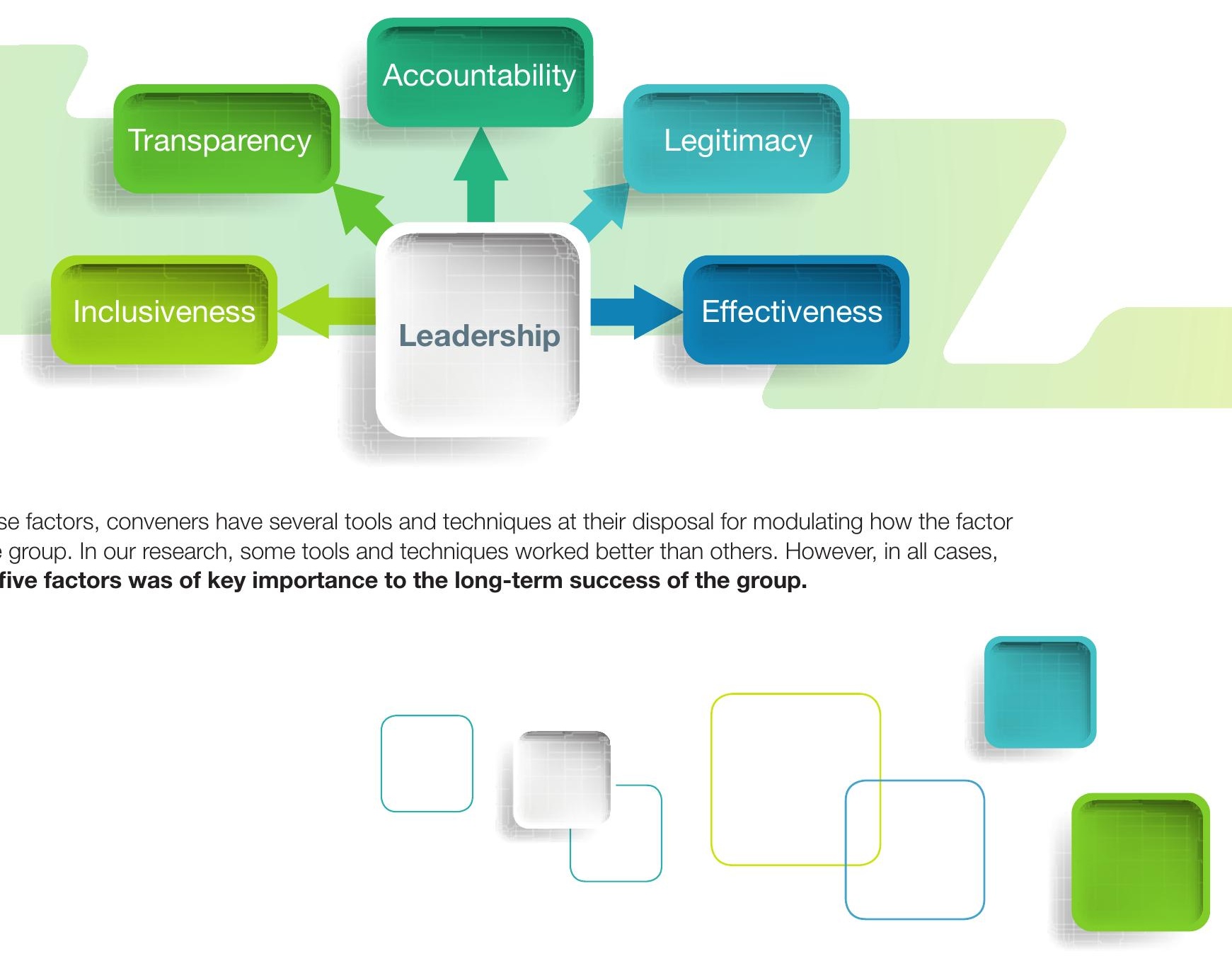

Within each of these factors, conveners have several tools and techniques at their disposal for modulating how the factor is expressed in the group. In our research, some tools and techniques worked better than others. However, in all cases, balancing these five factors was of key importance to the long-term success of the group. 
FRAMEWORK CONDITION: INCLUSIVENESS

\title{
Possible Tools and Techniques
}

\author{
Curation of stakeholders \\ Alternative participation mechanisms \\ Participatory technologies (e.g., livestreaming, online platforms)
}

One factor critical to the success of governance groups is the degree to which they include a diverse array of participants and stakeholders. Being more inclusive is not necessarily in and of itself an objective. Instead, a convener must carefully balance inclusion against other competing factors. For example, including greater numbers of stakeholders may make a governance group unwieldy or slow, or might make consensus impossible. By the same token, failing to include a sufficient number of stakeholders may make implementation impossible. For that reason, inclusiveness must be carefully tailored to the needs of the group, so as to maximize the degree and diversity of participation, without compromising the overall objectives of the group.

Inclusiveness should be considered in two different ways: (1) who gets to participate; and (2) how different stakeholders participate. Conveners can adjust both of these aspects independently in order to shape the overall inclusiveness of the group.

\section{Who Participates}

Identifying stakeholders for formal inclusion is a critical step in the convening process. At the earliest stages of forming a governance group, conveners must consider which actors have a stake in the governance process, and which should be included, formally or informally, in the group.
In almost every case study, conveners curated the participants by exercising some level of control and discretion over the number and types of participants. There are many reasons why conveners would want to exercise control over the selection of participating stakeholders. Perhaps the most common rationale for participant curation is to ensure that participants have a significant nexus to the topic at hand. In other instances, practical constraints such as space and funding limitations justified the curation of participants.

Depending on the reason for curation, a group may need to develop specific criteria for inclusion. For example, some of the groups we studied used criteria such as the level of economic investment or technical expertise in order to determine who could participate.
Although decisions about inclusion can be contentious, effective governance groups often approach the issue instrumentally. In other words, the conveners use different configurations of participants (even within the lifecycle of a single group) in order to achieve strategic aims. Interestingly, our case studies do not evidence many, if any, detrimental effects from this instrumental approach. We suspect that the reason why is because no matter how instrumental and tactical a convener is in selecting participants, a successful outcome often requires the full buy-in and participation of critical stakeholders. For that reason, a group must always be sufficiently inclusive as to maintain the support of all of those stakeholders necessary for developing and implementing a solution.

\section{Resource Asymmetries}

When thinking about inclusiveness, it is important to keep in mind that formal participatory roles or tools can increase inclusiveness only if participants have the ability and resources to take advantage of those opportunities. In several of the case studies, factors such as lack of time, limited finances, and lack of knowledge or experience placed considerable limits on the ability of certain stakeholders to participate fully and effectively. In some cases, under-resourced participants may have even ended up worse off by participating.

It is certainly possible to overcome these limitations and asymmetries, but it generally requires both time and money. Addressing these asymmetries in governance groups is important for increasing inclusiveness, but the difficulty of doing so should not be underestimated. 


\section{How to Participate}

Participation is important because it is a means to an end-it provides the opportunity to shape the final outcomes of the group. That means that how stakeholders can shape that outcome is equally as important as who gets to participate.

There are many ways stakeholders can participate in decision-making, ranging from formal mechanisms like consensus and voting to more informal mechanisms. In some cases, governance groups use different decision-making processes at the same time in different parts of the same organization. Just like when selecting who to include, effective governance groups often select their decision-making processes instrumentally.

In most cases, groups prefer using consensus and often begin with that as a default. However, our research shows that governance groups will revert to voting where consensus cannot be reached and a solution can still be implemented over objections. When a group reverts to voting, it means there are likely winners and losers. Thus, a governance group should only switch to voting when the outcome can be implemented over the objections of the losing stakeholders. We observed this most frequently where there was an accepted regulatory or legal authority that could be called on to compel implementation or enforcement of an outcome over the objections of the losing stakeholders.

Switching from consensus to voting may have an additional cost of negatively changing participant behavior. Because voting is less collaborative than consensus, switching to voting may signal that it is acceptable to be more adversarial. In other words, a switch to voting when there is disagreement may itself trigger greater disagreement.
Beyond decision-making processes, conveners must also address questions about methods of contribution. Inperson participation is only one possible method of inclusion. The case studies demonstrate an array of alternative participatory mechanisms, some more effective than others.

In several case studies, groups used technology to enable wider opportunities for participation. In some cases, this was an effective way to "bring into the room" participants who otherwise would be unable to participate in the process. That said,

participatory technologies will not themselves automatically generate greater inclusiveness. Like any tool, participatory technologies must be used with intent and purpose. In groups where conveners did not embrace the technology or the technology was not fully integrated into the workflow, technological tools were less effective. Participatory tools are not a panacea, but are instead a useful tool for conveners to deploy thoughtfully in ways that are integrated into the governance groups as a whole.

The case studies also contain examples of more informal participatory mechanisms. Several case studies highlight the role of working groups as a way of including more voices in the process. Generally, these working groups assume responsibility for less controversial or more technical issues, which reduces friction and simplifies the decision-making process while also including a broader array of viewpoints.

\section{Inclusiveness In Action: NETmundial}

Broad inclusion was a critical source of legitimacy in the NETmundial meeting (see Mini Case Study \#2), and the organizers used a variety of technological tools throughout the process in order to increase the opportunities for participation. For example, over 1,000 remote participants were able to use Adobe Connect to livestream the meeting. The organizers structured the debate so that each group would have equal voice with separate microphones for each stakeholder group (government, business, academia/technical community, civil society, and remote hubs) and rotated through the microphones. In addition, translators worked on site to translate the discussion in real time into a number of languages for participants in the room and at the remote hubs.

Resource asymmetries, however, posed a challenge for inclusiveness. The cost of traveling to São Paulo to attend the meeting may have been prohibitive for some, and the organizers were not able to arrange travel-funding support until just prior to the event. This meant that some stakeholders were not able to attend.

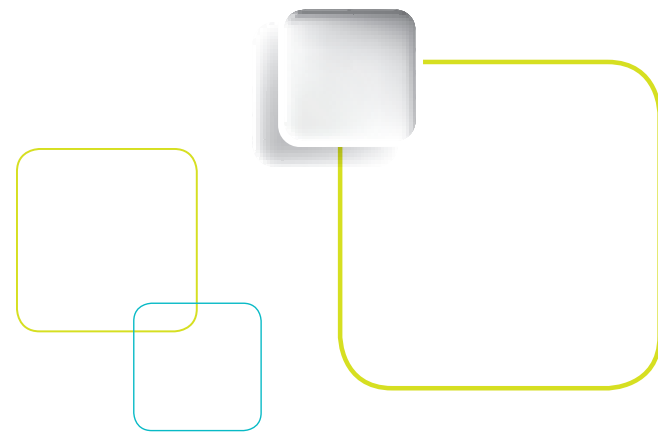




\section{FRAMEWORK CONDITION: TRANSPARENCY}

\section{Possible Tools and Techniques}

Livestreaming or other forms of real-time communication

A comprehensive online public database of reports and decisions Clearly established communications pathways between the group and existing institutions

Within the case studies, transparency spanned a wide spectrum, from very limited openness to fairly radical depths of transparency. Although the cases used different approaches to, and levels of, transparency, in many cases the driving motivation was the same: what approach would best support the identification and implementation of a solution? Conveners of governance groups instrumentally adjusted the transparency of the group, increasing it when it would aid the deliberative process, and reducing it when it would be a hindrance.

\section{In assessing whether more or less transparency would be helpful to the governance group, it is important to pay attention to the background and previous experiences of the stakeholders and participants. Our} research suggests that the most effective level of transparency may be a reflection of the existing norms of the community. A community that is primed to be suspect of transparency (e.g., a business accustomed to secret negotiations) is more likely to believe transparency will be a hindrance to a successful deliberation. Our research found successful groups across the full spectrum of transparency options. This does not mean that any level of transparency will work for any group, but instead indicates that effective groups use a level of transparency that is generally well matched to the expectations of the stakeholders.

A convener of a governance group can manage the group's transparency through three key aspects:

communication, knowledge and memory management, and interfaces with other institutions.

\section{Communication}

Perhaps the most central element of transparency is communication with stakeholders and the public with respect to the decision-making process of the group. External communication helps outside observers understand the process and outcome, ultimately helping build support for the work of the group and enhancing the perceived legitimacy of the outcome. When successful, communication (often enabled by Internet technologies) can even extend the breadth and depth of participation in the process itself, enabling farflung interactions and creating a multidirectional communications stream. Internal communication is also important for effective governance groups. Internal communication helps participants contribute more effectively to the outcome of a group. Poor or nonexistent internal communications can lead to wasted or duplicated effort, and untimely communications may leave participants feeling underprepared.

\section{Knowledge and Memory Management}

Maintaining knowledge and building institutional memory lends transparency to a governance group over time, offering insight into past decisions. Approaches to knowledge management differ primarily in the ease by which knowledge can be accessed and applied to future decision-making.

Our research covered several approaches to memory management. In one case, institutional memory resided almost entirely within the individual memories of staff. Such an approach is less transparent because it relies upon the availability and memory of certain key individuals. In other cases, groups used comprehensive, public, online databases for storing key documents and decisions, which lowers the cost of acting on institutional knowledge and reduces points of failure.

\section{Interfaces and Coupling Management}

A third aspect of transparency relates to how groups operate within a network of existing institutions. Groups often have formal and informal mechanisms for interacting with existing institutions, particularly government bodies. The EIDG ${ }^{2}$ (see Mini Case Study \#1) is a good example of a formal interface between group and government. The EIDG was established to help improve legislative outcomes, so it was important to have clear and formal pathways between the group and the legislative process. Having members of parliament play an active role within the group was a critical element of the interface. While the EIDG lacked a formal mechanism for turning proposals into legislation, the active engagement of governmental actors created a pathway to ease the creation and introduction of such legislation.

In other cases the interfaces between groups and government are more informal. In the Swiss ComCom Roundtables, for example, formal governmental involvement was limited to a convening role. Instead, the primary governmental interface was the threat of future regulation in the event that stakeholders failed to reach a suitable agreement. In this case, the parties participated in the Roundtable process out of a desire to avoid a more formal interface with government. 


\section{Transparency In Action: Swiss ComCom Roundtable ${ }^{3}$}

The Swiss ComCom Roundtable was a multistakeholder process convened to help private sector firms deploy in a coordinated fashion a fiber optic network connected to every home in Switzerland. In this case, transparency was relatively limited. Because the debates involved sensitive issues of strategic importance to the industry players involved, the organizer, the government regulator Swiss ComCom, concluded that confidentiality was critical to facilitating a robust discussion and achieving compromise. The parties agreed that all communications about the Roundtable would come from ComCom, and the participants would not comment about the process. Despite the lack of transparency, the Roundtable was generally considered successful. However, one participant suggested the lack of transparency enabled ComCom to overstate its role in the process.

\section{FRAMEWORK CONDITION: ACCOUNTABILITY}

Possible Tools and Techniques
Voting or other formal mechanisms for oversight
Transparency
Defection

Our research found a number of tools through which the unbridled operation of a governance group could be restrained. These limitations can take many forms, and are often linked to the mode of decision-making that the group adopts. Such constraints may include voting for (or removing) key decision makers, leaving the governance group for alternatives, subjecting group decisions to oversight panels, offering opportunities for public deliberation and protest, and requiring various forms of transparency, among others.

Selecting the appropriate mechanisms for accountability heavily depends on the context in which the group operates. For example, where formal regulatory or legal authority underlies the operation of the governance group, the use of

voting or oversight committees appears to fit quite naturally as an accountability tool. However, in the absence of regulatory authority, it is often easier for stakeholders to leave the governance group and create alternatives, meaning that defection and transparency might be more effective levers of accountability.

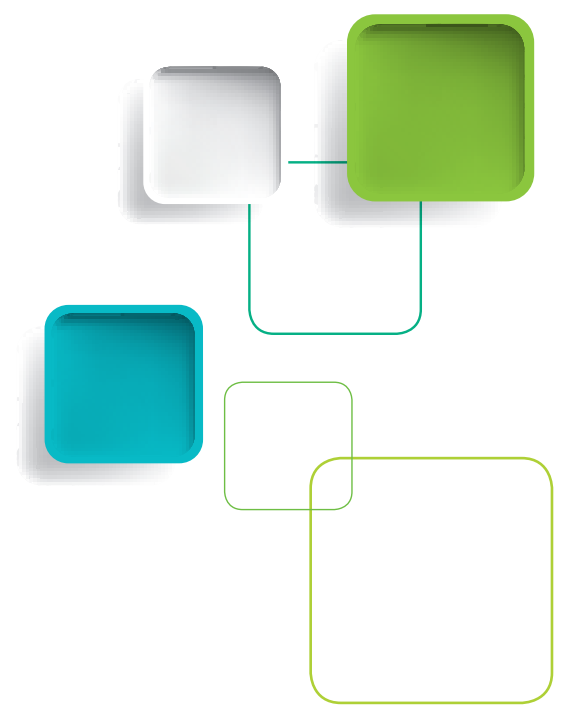

\section{Accountability In Action: Bitcoin}

The Bitcoin case study illustrates how the threat of defection can be a useful accountability mechanism. In order for Bitcoin, the decentralized digital currency, to succeed, the developers believed it was important to maintain a unified Bitcoin architecture. The key developers noted that the ease by which someone could fork the code and create a competing system meant that the costs of defecting to an alternative were very low. This threat of defection forced the group to be conservative in their actions in order to avoid dividing the stakeholder community. 


\section{FRAMEWORK CONDITION: LEGITIMACY}

\section{Possible Tools and Techniques}

Transparent and democratic processes for selecting stakeholders Clear and accountable mechanisms for incorporating inputs from the public

Clearly defined and measurable goals
Legitimacy is most important to governance groups when conflicts arise. In domains that are more politicized or where the positions of stakeholders are more divergent, legitimacy is more frequently called into question. In these instances, "stronger" forms of legitimacy are needed. Where there is broad approval of the process and its objectives, "lighter" forms of legitimacy can suffice. As a result, effective governance groups often rely upon multiple and overlapping sources of legitimacy, moving between them depending on the circumstances and context.

Legitimacy can manifest through input legitimacy or output legitimacy. Input legitimacy refers to perceptions of a fair process. By contrast, output legitimacy is where the quality of the output ensures it is seen as legitimate among stakeholders (i.e., the ends justify the means). Whether input or output legitimacy is more important depends on the context. For example, in the wake of the Snowden revelations, most stakeholders in the Internet governance community agreed upon the need to stage a public discussion about Internet governance. However, the appropriate process and platform for holding that debate was highly contested, making the fairness of the NETmundial process a critical component of the event's legitimacy. In other cases, output legitimacy is more central to the success of the group. For example, in the Swiss ComCom Roundtables, the outcome was an agreement that improved the deployment of fiber optic cable across Switzerland. Despite concerns over inclusion of stakeholders within the process, the Roundtables were considered legitimate due to the success of the outcome.

\section{Legitimacy In Action: CT-Spam}

In many cases governance groups strive to be viewed as legitimate at the conclusion of their work. The CT-Spam governance group, a group formed to reduce spam in Brazil, is a rare case in which legitimacy was not an end in and of itself for the governance process. The CT-Spam group did not need continued legitimacy because the technical change was a one-time event; once implemented it would not require continued buy-in and reaffirmation from stakeholders.

However, legitimacy was important to the CT-Spam group at a much earlier point in its lifecycle. When Brazil initially tried to address its spam problem, it faced pushback from key stakeholders who were concerned about the proposed technical solution. The CT-Spam group was then created in order to educate and obtain buy-in from those stakeholders. The legitimacy of the CT-Spam group enabled the approval of the same technical change that was previously considered impossible.

\section{FRAMEWORK CONDITION: EFFECTIVENESS}

\section{Possible Tools and Techniques}

Clearly defined and communicated objectives

Operational timelines for group activities

Mechanisms to communicate group operations and accomplishments to stakeholders and the public
The effectiveness of governance groups is typically assessed after the fact, but that does not mean that the convener of a governance group can ignore this issue at the outset. In fact, the opposite is true: there are things that can be done early on that can contribute to the group's eventual effectiveness.

Conveners should consider effectiveness with respect to the areas of outcomes, unintended consequences, and operational continuity. 


\section{Outcomes}

Effective groups have clearly defined objectives that help guide the group to its goals. Clearly defined goals have two benefits with respect to effectiveness. First, a group will be deemed effective depending on how well it met expectations and achieved its goals, and those expectations can be shaped by clearly defined goals at the outset. Second, vagueness around a group's goals can obfuscate the process of achieving consensus and increase the vulnerability to political pressure. For example, a number of EIDG members expressed regret regarding what they perceived to be the overly broad focus of the Commission. They felt that if the group had a more clear and narrowly defined objective, the Commission might have achieved more significant results.

Governance groups can also improve their effectiveness by separating more technical decisions from policy ones. This division allows groups to reach agreement on more issues by enabling them to resolve less controversial decisions without resolving all of the policy issues that may have motivated the formation of the governance group in the first place.

\section{Unintended Consequences}

Effective groups anticipate how their decisions may interact with external factors in order to prevent unintended consequences. In our research, unintended consequences seemed to occur when a group failed to think about how their work would interact with the environment. What may seem good in the abstract may appear quite different when the economic, political, social, and cultural environment is considered.

For example, in Switzerland, an agreement to deploy four fiber optic cables shared between the telecommunications companies and the local utilities seemed like a good idea in theory. In practice, however, the agreement had significant unintended effects on the utility companies and the utilization of their fiber because of the economics of content licensing. The utilities were at a competitive disadvantage against the telecommunications incumbent, who could negotiate more attractive license agreements at the national level instead of the local level. The failure to see the connection between the economic context and the agreement led to this unintended consequence.

\section{Operational Continuity}

Effective groups do not just identify solutions, but they also help implement them. With the exception of EIDG, our case studies did not include any examples of organizations that completely disbanded after identifying solutions to the problems they were formed to address. This may be a result of the small sample size, but it may also reflect the fact that few solutions are self-executing. Where political pressure was still needed, some groups maintained operation of their alliances and networks in order to keep pushing for legislative progress and to monitor enforcement. In other cases, active pressure and work was no longer needed, but the group was never formally disbanded, leaving open the possibility for it to be reconstituted if needed in the future should implementation not succeed on its own.

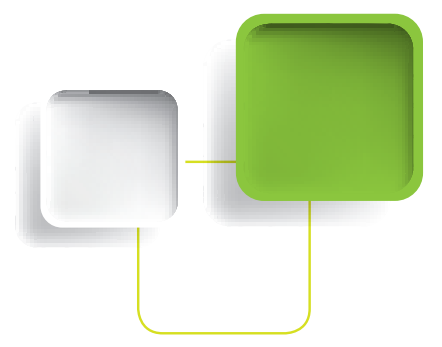

\section{Effectiveness In Action: Marco Civil ${ }^{6}$}

The Marco Civil is landmark legislation that provides an Internet Bill of Rights for Brazil. The process of drafting this legislation was effective in three ways. First, it achieved its clear objective: drafting and passing a bill of rights for the Internet. Second, the process built the community necessary to achieve implementation. Members of the public, government, global and local Internet companies, civil society, and others engaged in negotiations over the legislation's text, largely mediated through online platforms. Through these discussions and collaborative drafting, ongoing alliances were built that became important for obtaining the eventual passage of the bill and monitoring its enforcement.

Third, the group remained aware of the political environment in which it operated and leveraged that environment for the ultimate passing of the bill. The process faced many delays due to pushback within stakeholder groups, ultimately taking seven years to move from its initial inception into law. The Snowden disclosures provided an opportunity for the group, adding new urgency to the passage of the Marco Civil. The group was able to take advantage of this changed political environment in order to achieve its objectives. 


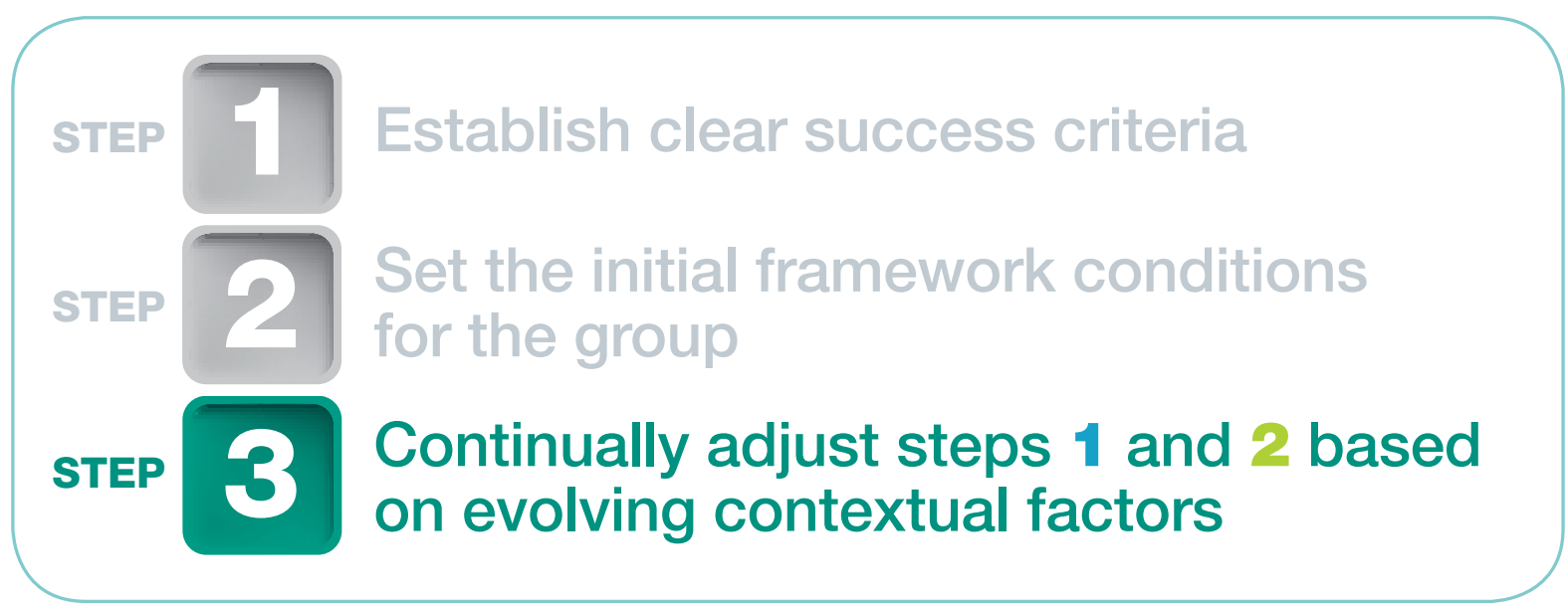

The final step of the process is the recognition that effective governance groups change over time in response to changing context, circumstances, and needs. No amount of careful planning in Steps 1 and 2 can fully anticipate every issue or how events may change in the future. As governance groups pass through different phases of operation, group conveners must remain alert to changes in circumstances that require adjustments to the approaches, mechanisms, and tools that they deploy in order to address evolving challenges from inside and outside.

The diagram to the right highlights the positive feedback loop that effective groups utilize. On the left side are the group's decisions about purpose, who to include, and how decisions are made. On the right side are internal and external reactions, including the public perception, the internal reception of stakeholders, the perceived legitimacy, and the perceived effectiveness. And underlying all of this is the evolving context and circumstances. The group's decisions shape the reactive factors, which in turn reshape

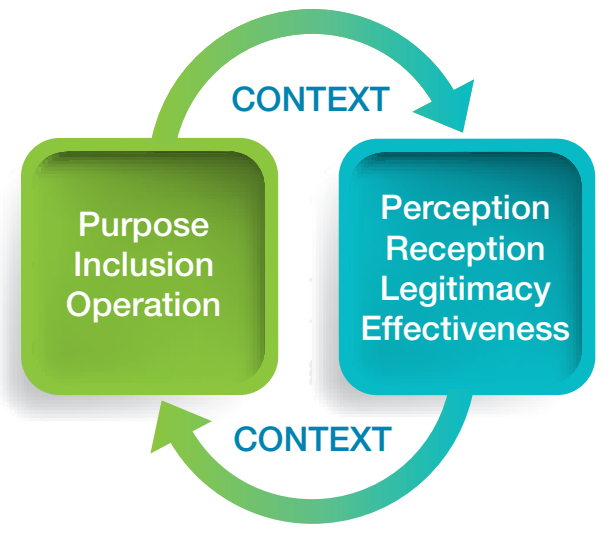
group decisions, while both are shaped by context.

In effective groups, conveners adjust these elements over time, modifying purpose, inclusion, and operation as necessary. We observed this in our research, for each of these elements:

Purpose: The most successful of our case studies involved governance groups that tailored their processes to their criteria of success. But to maintain that fit, as processes evolve, purpose must be adjusted as well. In one case, stakeholders noted how they failed to adjust their objectives in response to the political context, which allowed for increased politicization.

\begin{abstract}
Inclusiveness: The inclusiveness of governance groups often changes over time. Conveners use different configurations of participants in order to achieve strategic aims and respond to the evolving needs of the group. In one case, in response to complaints about excluding certain stakeholders, the group allowed those organizations to present their ideas through other forums.
\end{abstract}

\begin{abstract}
Operation: Governance groups often adopt different strategies for transparency and decision-making within the lifecycle of the group. For example, NETmundial had both radically transparent and less transparent aspects of its drafting process. And EIDG used a mix of both consensus and voting for decision-making.
\end{abstract}

\section{Conclusion}

Governance groups can be most impactful in some of the most challenging environments: where formal regulation cannot or does not exist. Our case study research helps us understand that despite the challenging circumstances in which they operate, governance groups can succeed, largely through remaining aware of, and adapting to, the evolving contextual environment in which they are embedded. We hope that by following these three steps and applying the lessons from the case studies, conveners and leaders of future governance groups can better understand and dynamically deploy the full range of tools and mechanisms available to them. 


\section{Mini Case Study \# 1}

\section{Enquete-Kommission Internet und digitale Gesellschaft ("EIDG")}

The Enquete Commission on Internet and Digital Society was a parliamentary inquiry body of the German Bundestag, which conducted its work between May 2010 and April 2013. Enquete Commissions are special bodies of the Bundestag, and form an interface between policymakers, academics, and professional experts in order to consider broad and complex societal issues that cannot be dealt with sufficiently through regular legislative processes. The EIDG was formed to consider the challenges digitization presents for politics and society.

The EIDG included 34 members, including 17 experts and practitioners from industry, trade unions, civil society and academia and 17 democratically elected members of parliament. It was structured around working groups designed to address different aspects of the topic. The working groups used public and private meetings and drafted preliminary reports for discussion by the broader group. The public was also incorporated through an online platform, although delays in implementation meant public participation was limited and could not be fully integrated into the EIDG's working procedure.

Political influences had a noticeable impact on the EIDG. While its links to the Bundestag guaranteed resources

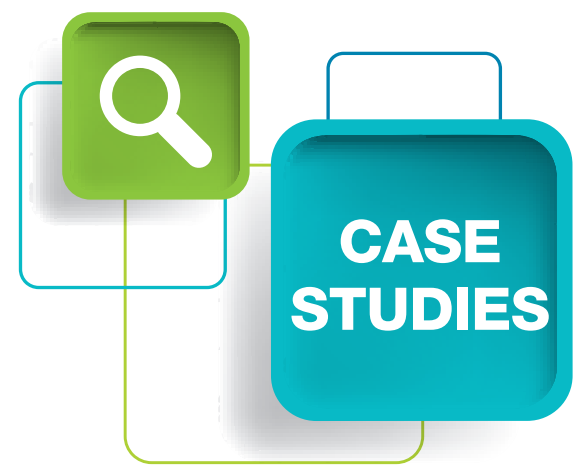

and stability for the process, these links also tied the Commission's work to political dynamics. Although formally independent, experts on the Commission were appointed by members of political parties and thus were expected to align with their party's views on specific issues. Furthermore, the use of majority voting on certain issues inhibited consensus building. Despite these detractions, the process enabled policymakers to integrate knowledge from a range of experts on very nuanced and complex issues, helping to develop a more substantial grounding for future Internet policymaking in Germany.

\section{Mini Case Study \#2}

\section{The Global Multistakeholder Meeting on the Future of Internet Governance ("NETmundial")}

NETmundial was held in São Paulo, Brazil on April 23rd and 24th 2014, and convened a range of representatives from government, intergovernmental organizations, academia, the technical community, the private sector, and civil society to discuss a set of principles and a roadmap for the future of Internet governance. Catalyzed by the revelations of mass surveillance of communications, the meeting served as a "laboratory" for global multistakeholder governance.

Its organization was designed around several levels of participation: a set of organizing committees were responsible for designing and executing the event, an online platform was used to collate inputs from the public, and a public event was held to debate the issues at hand, with a drafting committee responsible for synthesizing the final outcome document in real time. Each stage of the process aimed to incorporate representatives from each stakeholder group, but operated with differing levels of transparency, accountability, and inclusion.

For example, the organizing committees were put together in haste, and thus without transparent mechanisms for who would be appointed to each stakeholder seat. Still, having committees in charge of specific aspects of the meeting played an important role in channeling concerns and opinions early on in the process. Substantial resources were expended in order to incorporate broad public participation in the event. Many of these tools were technological, and they were designed to enable stakeholders around the globe not only to listen in but actively participate and ask questions throughout the process. While these tools may have increased transparency of the process, they failed to account for resource asymmetries among some participants, such as excluding non-English speakers or those who lacked connectivity to access these tools.

Despite these procedural imperfections, NETmundial was the first of its kind for having achieved a bottom-up multistakeholder document, and it has received positive reactions throughout the Internet governance ecosystem. 


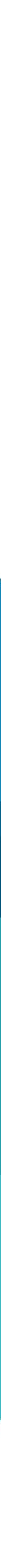

This abridged version of the synthesis of the full report has been made possible by a Google Faculty Research Award to Professor Urs Gasser, see http://research.google.com/university/relations/research awards.html.

\section{ENDNOTES}

1 The case study is available for review and comment at https://publixphere.net/i/noc/page/IG_Case_Study_NETMundial.

2 The case study is available for review and comment at

https://publixphere.net/i/noc/page/IG_Case_Study_EnqueteKommission_Internet_und_digitale_Gesellschaft.

3 The case study is available for review and comment at https://publixphere.net/i/noc/page/IG_Case_Study_Swiss_ComCom_FTTH_Roundtable.

4 The case study is available for review and comment at https://publixphere.net/i/noc/page/IG_Case_Study_Bitcoin_and_Autonomous_Systems.

5 The case study is available for review and comment at https://publixphere.net/i/noc/page//G_Case_Study_Fighting_Spam_the_Multistakeholder_Way.

6 The case study is available for review and comment at https://publixphere.net/i/noc/page//G_Case_Study_A_Bill_of_Rights_for_the_Brazilian_Internet. 
